\title{
Effects of Added Sodium Alginate on Mechanical Strength of Apatite Cement
}

\author{
Shinya TAJIMA ${ }^{1}$, Norihiko NISHIMOTO ${ }^{1}$, Yuji KISHI ${ }^{1}$, Shigeki MATSUYA ${ }^{2}$ and Kunio ISHIKAWA ${ }^{2}$ \\ ${ }^{1}$ Japan Institute for Advanced Dentistry, Shiba TK building 4F, 1-8-25, Shiba, Minatoku, Tokyo 105-0014, Japan \\ ${ }^{2}$ Department of Biomaterials, Faculty of Dental Science, Kyushu University, 3-1-1 Maidashi, Higashiku, Fukuoka 812-8582, \\ Japan \\ Corresponding author, E-mail:ishikawa@dent.kyushu-u.ac.jp
}

Received April 22, 2004/Accepted June 25, 2004

Effects of added sodium alginate on the mechanical strength of Biopex ${ }^{\circledR}$, one type of apatite cement, were investigated since sodium alginate addition is very effective for Biopex ${ }^{\circledR}$ to acquire anti-washout property. Addition of sodium alginate into the liquid phase of Biopex ${ }^{\circledR}$ resulted in a slower transformation to apatitic monolith. As a result, mechanical strength of set Biopex ${ }^{\circledR 3}$ in terms of diametral tensile strength (DTS) decreased when it was hardened in an incubator kept at $37^{\circ} \mathrm{C}$ and $100 \%$ relative humidity for 7 days. However, DTS value increased with increase in the amount of added sodium alginate when the Biopex ${ }^{\circledR}$ paste was immersed in $0.9 \%$ saline at $37^{\circ} \mathrm{C}$ for 7 days. Set Biopex ${ }^{\circledR}$ with less sodium alginate also showed larger porosity. Based on these findings, we concluded that added sodium alginate was effective in increasing the mechanical strength of Biopex ${ }^{\circledR}$ by inhibiting liquid penetration into its paste when it is exposed to body fluids.

Key words: Apatite cement, Sodium alginate, Mechanical strength

\section{INTRODUCTION}

In 1976, Monma and Goto reported that $\alpha$-tricalcium phosphate set to form calcium-deficient hydroxyapatite with $\mathrm{Ca} / \mathrm{P}$ molar ratio of 1.5 when $\alpha$-tricalcium phosphate was hydrated in water at 60 $100^{\circ} \mathrm{C}$ and $\mathrm{pH}$ between 8.1 and $11.4^{1)}$. Although this was the initial finding of apatite cement, long setting time prevented its clinical use for a long period. In 1986, Brown and Chow reported that a mixture of tetracalcium phosphate (TTCP: $\mathrm{Ca}_{4}\left(\mathrm{PO}_{4}\right)_{2} \mathrm{O}$ ) and dicalcium phosphate anhydrous $\left(\right.$ DCPA: $\left.\mathrm{CaHPO}_{4}\right)$ set within approximately 30-60 minutes at physiological temperature, and that it formed an apatitic phase when mixed with aqueous solution ${ }^{2,3)}$. Based on their initial findings, many types of apatite cement have since been studied and developed ${ }^{4-31)}$. Since apatite cements transform to apatitic monolith upon setting reaction, excellent tissue response and good osteoconductivity are reported - similar to other apatite related biomaterials ${ }^{32-37)}$. Although apatite cements are the promising biomaterials aimed for bone defects reconstruction, it should be noted that apatite cements show excellent tissue response and good osteoconductivity only when they become monolithic. In other words, apatite cements cause inflammatory response when they are washed out or crumbled $^{38)}$. Therefore, apatite cement should be used only after complete hemostasis or in selected clinical cases where setting reaction of apatite cement could be guaranteed. In many actual circumstances, however, surgeons or dentists detect bleeding even when they thought complete hemostasis has taken place. Therefore, it is obviously necessary to develop an apatite cement that will set even if it faces plenty of body fluids. We have previously reported that addition of gelling agents was very effective for the apatite cement that consisted of an equimolar mixture of TTCP and DCPA to acquire anti-washout ability ${ }^{5,11,21-25,30)}$. For example, the apatite cement paste would not be washed out even when it was immersed in serum immediately after mixing, if only as little as $0.5 \%$ of sodium alginate was added into the liquid phase of apatite cement. On the other hand, apatite cement paste containing no sodium alginate would be washed out immediately upon exposure to the liquid phase ${ }^{5,11)}$.

Currently, Biopex ${ }^{\circledR}$ is the only apatite cement commercially available in Japan. Although detailed composition of Biopex ${ }^{\circledR}$ is not open to the public, the powder phase of Biopex ${ }^{\circledR}$ is mainly a $\alpha$-tricalcium phosphate $\left(\alpha\right.$-TCP: $\left.\alpha-\mathrm{Ca}_{3}\left(\mathrm{PO}_{4}\right)_{2}\right)$, and it also contains tetracalcium phosphate (TTCP: $\left.\mathrm{Ca}_{4}\left(\mathrm{PO}_{4}\right)_{2} \mathrm{O}\right)$ and dicalcium phosphate dihydrate (DCPD: $\mathrm{CaHPO}_{4} \cdot 2 \mathrm{H}_{2} \mathrm{O}$ ). The liquid phase, on the other hand, is mainly an aqueous solution of a chondroitin sulfate sodium salt and succinic acid disodium salt ${ }^{22,27)}$. Besides these components, magnesium phosphate $\left(\mathrm{Mg}_{3}\left(\mathrm{PO}_{4}\right)_{2}\right)$ and sodium hydrogen sulfite were added to its powder and liquid phases to allow reservation of the cement at room temperature ${ }^{22,27)}$. Basically, Biopex ${ }^{\circledR}$ shows better anti-washout property than Bone Source ${ }^{\circledR}$ (which consists of an equimolar mixture of TTCP and DCPA), since succinic acid disodium salt results in viscous liquid phase ${ }^{22)}$. However, Biopex ${ }^{\circledR}$ would still be washed out if the paste is immersed in serum immediately after mixing. In fact, the washout property of Biopex ${ }^{(B)}$ is claimed as its serious shortcoming. We have also reported that Biopex ${ }^{\circledR}$ could acquire anti-washout property just by introducing 
sodium alginate into its liquid phase ${ }^{22)}$. However, how added sodium alginate would affect the mechanical strength of set Biopex ${ }^{\circledR}$ is yet to be evaluated.

In the present investigation, therefore, we evaluated the mechanical strength of Biopex ${ }^{\circledR}$ containing 0-0.9 wt\% sodium alginate in its liquid phase. In one condition, Biopex ${ }^{\circledR}$ was kept in an incubator to exclude the effect of liquid penetration. In the other condition, Biopex ${ }^{\circledR}$ was immersed in saline to simulate the case when the paste is exposed to body fluid after initial hemostasis.

\section{MATERIALS AND METHODS}

Biopex ${ }^{\circledR}$ was kindly donated by Mitsubishi Materials (Tokyo, Japan) for this investigation. Using a glass slab and spatula, we mixed the powder and liquid phases of Biopex ${ }^{\otimes}$ at a liquid to powder ratio (L/P) of $0.3 \mathrm{~mL} / \mathrm{g}$, and then placed the cement paste in a split mold (6-mm diameter, 3-mm height). Both ends of the mold were covered by glass plates, clamped, and the paste pre-hardened by storing in an incubator kept at $37^{\circ} \mathrm{C}$ and $100 \%$ relative humidity for 1 minute since immediate exposure of Biopex ${ }^{\circledR}$ to saline results in paste washout. This process mimics a situation that the cement is prevented from exposure to body fluid for the initial one minute. In one group, the cement was further kept in the incubator for 1 day or 7 days to exclude the effect of liquid penetration into the cement. In the other group, the pre-hardened cement was immersed in $0.9 \%$ saline kept at $37^{\circ} \mathrm{C}$ for 1 day or 7 days to simulate the case that the cement was exposed to body fluid after initial hemostasis.

After being kept in the incubator or saline for 1 or 7 days, the mechanical strength of the cement was evaluated in terms of diametral tensile strength (DTS) without drying procedure. The diameter and length of each specimen were measured with a micrometer. The samples were crushed at a cross-head speed of $1 \mathrm{~mm} / \mathrm{min}$ using a universal testing machine (IS5000, Shimadzu, Kyoto, Japan). Each DTS value was the average value of at least five specimens. The bars in the figures denote standard deviation.

The composition of Biopex ${ }^{\circledR}$ was identified by means of X-ray diffraction (XRD) analysis. The specimens were ground into fine powders and characterized by XRD. The XRD patterns of the specimens were recorded with a vertically mounted diffractometer system (RINT 2500V, Rigaku, Tokyo, Japan) using counter-monochromatized $\mathrm{CuK} \alpha$ radiation generated at $40 \mathrm{kV}$ and $100 \mathrm{~mA}$. The samples were scanned from $3^{\circ}$ to $60^{\circ}$ in continuous mode $\left(2.0^{\circ} 2 \theta / \mathrm{min}\right)$, and the intensity was recorded at $0.02^{\circ}$ intervals. Note that only XRD patterns of 20 $45^{\circ}$ were presented since we found no important peaks other than this zone.

Porosity of the apatite cement was calculated by measuring the weight and volume of the cement. Porosity was calculated based on the assumption that cement composition was apatite at the density of 3.16 $\mathrm{g} / \mathrm{cm}^{3}$. The density was the average value of at least four specimens.

For statistical analysis, one-way factorial ANOVA and Fisher's PLSD method as a post-hoc test were performed using a software known as "Stat View 4.02" (Abacus Concepts Inc., Berkeley, California).

\section{RESULTS}

Fig. 1 shows the DTS values of Biopex ${ }^{\circledR}$ containing 0-0.9 wt\% sodium alginate in its liquid phase and allowed to set for 24 hours in the incubator or in saline. At this stage we found no significant differences based on the amount of added sodium alginate or the setting condition.

Fig. 2 summarizes the DTS values of Biopex ${ }^{B}$ containing 0-0.9 wt\% sodium alginate in its liquid phase and allowed to set for 7 days in the incubator or in saline. Mechanical strength of Biopex ${ }^{\circledR}$ increased regardless of the amount of added sodium alginate or the setting condition when compared with the results of Day 1. However, we found clear differences on the mechanical strength of Biopex ${ }^{\circledR}$ based on the amount of added sodium alginate and keeping

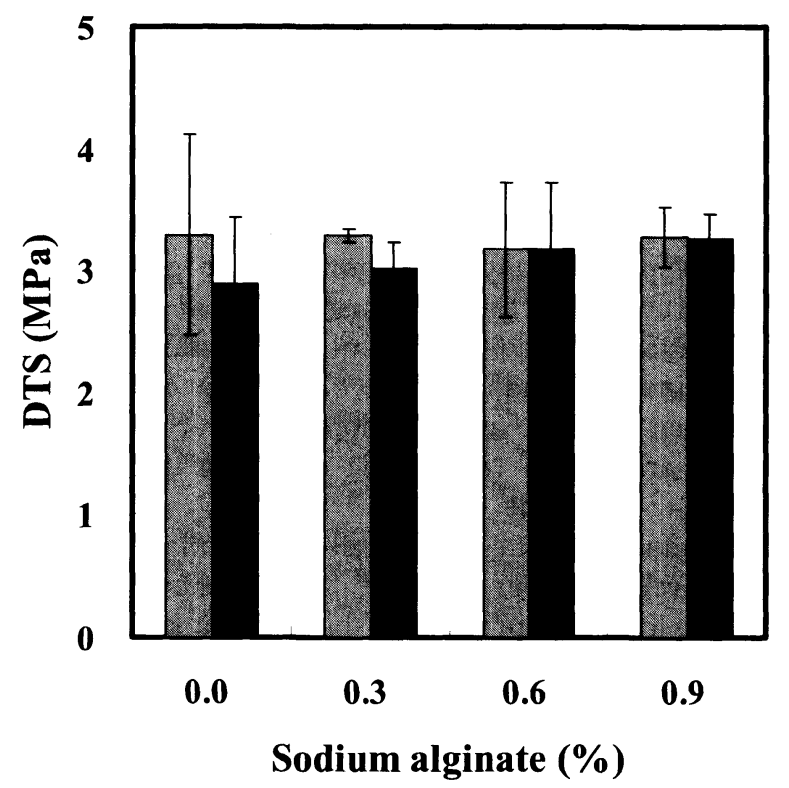

Fig. 1 Diametral tensile strength of Biopex ${ }^{\circledR}$ containing $0-0.9$ wt\% sodium alginate in its liquid phase when pre-hardened in an incubator kept at $37^{\circ} \mathrm{C}$ and $100 \%$ relative humidity for $1 \mathrm{~min}$ ute and (1) further kept in the incubator for 1 day or $(\square)$ immersed in $0.9 \%$ saline at $37^{\circ} \mathrm{C}$ for 1 day. Liquid to powder mixing ratio is 0.3 $\mathrm{mL} / \mathrm{g}$. The bar in the figure denotes standard deviation. 


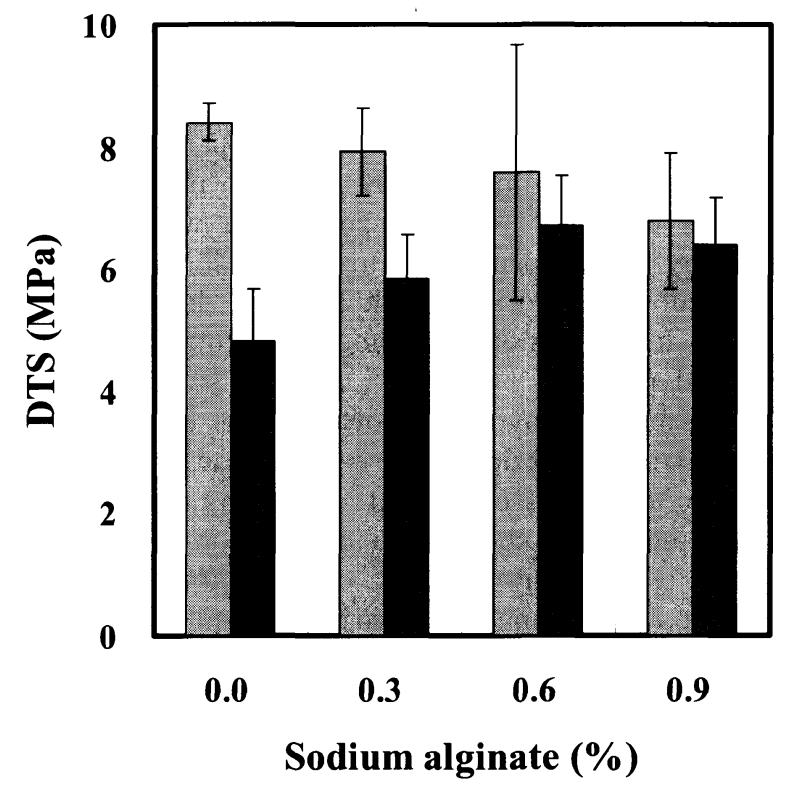

Fig. 2 Diametral tensile strength of Biopex ${ }^{\circledR}$ containing $0-0.9$ wt\% sodium alginate in its liquid phase when pre-hardened in an incubator kept at $37^{\circ} \mathrm{C}$ and $100 \%$ relative humidity for $1 \mathrm{~min}$ ute and (urther kept in the incubator for 7 days or ( $)$ immersed in $0.9 \%$ saline at 37 ${ }^{\circ} \mathrm{C}$ for 7 days. Liquid to powder mixing ratio is $0.3 \mathrm{~mL} / \mathrm{g}$. The bar in the figure denotes standard deviation.

condition. When Biopex ${ }^{\circledR}$ was allowed to set in the incubator, DTS value decreased with an increase in the amount of added sodium alginate. In contrast, DTS value of Biopex ${ }^{\circledR}$ kept in the saline increased with increase in the amount of added sodium alginate. DTS value of Biopex ${ }^{\circledR}$ kept in the incubator was significantly $(\mathrm{p}<0.01)$ higher when compared with that kept in the saline except for Biopex ${ }^{\circledR}$ that contained 0.6 or 0.9 wt $\%$ sodium alginate in its liquid phase - those showed no significant differences.

Fig. 3 summarizes the XRD patterns of the powder phase of Biopex ${ }^{\circledR}$ that contained 0-0.9 wt\% sodium alginate in its liquid phase and was kept in the incubator or immersed in the saline for 7 days. XRD patterns of the powder phase of Biopex ${ }^{\circledR}$ and apatite are also shown for comparison. We found apatite formation regardless of the amount of added sodium alginate or the setting condition. We also found unreacted $\alpha$-TCP in all specimens. Interestingly, we found larger amount of unreacted $\alpha$-TCP in specimens that contained larger amount of sodium alginate. For the same amount of sodium alginate, the amount of unreacted $\alpha$-TCP was smaller for the specimen that was immersed in the saline than that was kept in the incubator.

Table 1 summarizes the porosities of Biopex ${ }^{\circledR}$ that contained $0-0.9$ wt $\%$ sodium alginate and kept in the incubator or immersed in the saline for 7

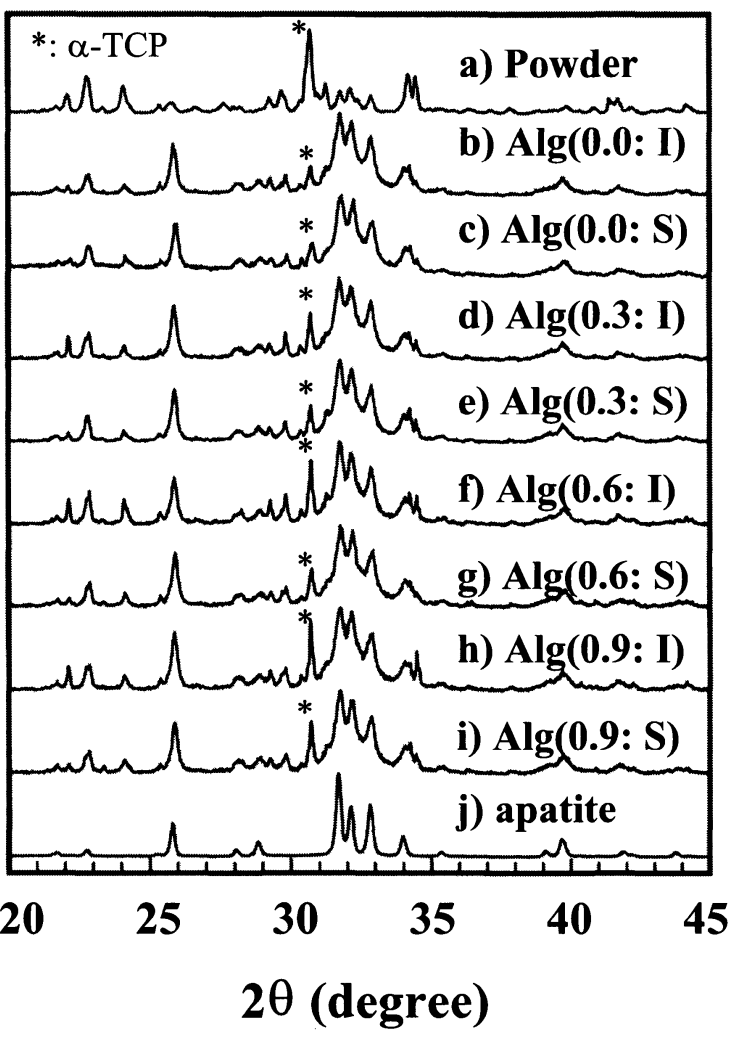

Fig. 3 Typical X-ray diffraction patterns of Biopex ${ }^{B}$ containing 0-0.9 wt\% sodium alginate in its liquid phase when pre-hardened in an incubator kept at $37^{\circ} \mathrm{C}$ and $100 \%$ relative humidity for 1 minute and further kept in the incubator for 7 days or immersed in saline at $37^{\circ} \mathrm{C}$ for 7 days. XRD patterns of powder phase of Biopex ${ }^{18}$ and apatite are also shown for comparison. Amount of sodium alginate added in the liquid phase of Biopex ${ }^{\circledR}$ is stated in the parentheses. The hardening condition, i.e., in the incubator (I) or in $0.9 \%$ saline $(\mathrm{S})$, is also stated in the parentheses. Liquid to powder mixing ratio is $0.3 \mathrm{~mL} / \mathrm{g}$. $\alpha$-TCP is denoted by $\left(^{*}\right)$.

Table 1 Porosity of Biopex ${ }^{\circledR}$ containing 0-0.9 wt\% sodium alginate in its liquid phase when pre-hardened in an incubator kept at $37^{\circ} \mathrm{C}$ and $100 \%$ relative humidity for $1 \mathrm{~min}$, and further kept in the incubator for 7 days or immersed in $0.9 \%$ saline at 37 ${ }^{\circ} \mathrm{C}$ for 7 days. Liquid to powder mixing ratio is $0.3 \mathrm{~mL} / \mathrm{g}$

\begin{tabular}{ccc}
\hline Sodium alginate $(w t \%)$ & Incubator & Saline \\
\hline 0.0 & $33.6 \pm 0.3$ & $37.6 \pm 1.6$ \\
0.3 & $33.6 \pm 0.5$ & $35.6 \pm 1.0$ \\
0.6 & $33.8 \pm 1.5$ & $35.2 \pm 1.5$ \\
0.9 & $34.0 \pm 0.5$ & $34.6 \pm 1.3$ \\
\hline
\end{tabular}


days. When Biopex ${ }^{\circledR}$ was kept in the incubator, we found no significant differences based on the amount of added sodium alginate. On the other hand, porosity of set Biopex ${ }^{\circledR}$ decreased with an increase in the amount of added sodium alginate when Biopex ${ }^{\circledR}$ was immersed in the saline. Biopex ${ }^{\circledR}$ immersed in the saline showed significantly $(p<0.05)$ larger porosity when compared with Biopex ${ }^{\circledR}$ kept in the incubator, except for Biopex ${ }^{\circledR}$ that contained $0.9 \mathrm{wt} \%$ sodium alginate in its liquid phase - they showed no significant differences.

\section{DISCUSSION}

The results obtained in the present study clearly demonstrate that added sodium alginate affects the mechanical strength of Biopex ${ }^{\circledR}$ even when the paste would not be washed out. As shown in Fig. 2, increase in the amount of added sodium alginate resulted in decreased DTS value when the Biopex ${ }^{\circledR}$ paste was hardened in the incubator for 7 days. These results are consistent with the results reported for the apatite cement that consists of TTCP and $\mathrm{DCPA}^{5)}$. One of the reasons for decreased DTS could be the limited transformation to apatite, as shown in Fig. 3. We also found that the DTS value of Biopex ${ }^{\circledR}$ was the same regardless of the amount of added sodium alginate at Day 1, as shown in Fig. 1. Although difference in the results obtained at Day 1 and Day 7 has not been clarified in the present study, it may be attributed to the setting mechanism of Biopex ${ }^{\circledR}$. In other words, Biopex ${ }^{\circledR}$ sets upon the chelating reaction of succinic acid with calcium phosphate powder at the initial stage, and then gradually transforms to apatitic mineral due to dissolutionprecipitation reaction. Sodium alginate may not inhibit the chelating reaction of succinic acid with calcium phosphate powder. Thus, we found no significant differences based on the amount of added sodium alginate at Day 1. On the contrary, sodium alginate is known to form calcium alginate upon exposure to calcium ion. Therefore, transformation of apatite cement to apatitic mineral would be inhibited by introducing sodium alginate into apatite cement since calcium ion formed by the dissolution of calcium phosphate powder would be consumed by the sodium alginate.

Similarly, we also found that transformation of Biopex ${ }^{\circledR}$ to apatitic mineral was inhibited by introducing sodium alginate into the liquid phase of Biopex ${ }^{\circledR}$ when the paste was immersed in saline (Fig. 3). Although limited transformation to apatitic mineral should result in reduced DTS value, we found that DTS value of Biopex ${ }^{\circledR}$ at Day 7 increased with the amount of added sodium alginate. These results do not mean that limited transformation to apatitic mineral was enhanced for the higher DTS value; rather they indicate that there are other factors that reduced DTS value when the amount of added sodium alginate was smaller. It is thought that one factor is the penetration of liquid into the paste. In fact, immediate exposure of the Biope ${ }^{\circledR}$ paste to liquid phase results in liquid penetration into paste followed by paste washout ${ }^{22)}$. This speculation was also supported by the porosity measurements shown in Table 1. As shown, porosity of set Biopex ${ }^{\circledR}$ decreased with increase in the amount of added sodium alginate in its liquid phase.

This may be a nice opportunity to discuss about the setting reaction, porosity, and mechanical strength of apatite cement. Setting reaction of apatite cement is so-called a dissolution-precipitation process - similar to that of gypsum. In other words, powder phase of apatite cement dissolves to form calcium and phosphate ions, and these ions reprecipitate as apatite since apatite is the most stable phase thermodynamically at neutral and basic $\mathrm{pH}$ regions. As a result of dissolution-precipitation process, apatite cement would be a porous apatite monolith. It has been known that mechanical strength of porous materials follows an empirical equation, $S=$ $\mathrm{S}_{0} \exp (-\mathrm{bP})$, where $\mathrm{S}$ is the observed mechanical strength of the porous material, $\mathrm{S}_{0}$ is the ideal mechanical strength when there is no porosity, $\mathrm{P}$ is the porosity, and $\mathrm{b}$ is an empirical constant ${ }^{39)}$. In fact, DTS value of TTCP-DCPA type apatite cement



Fig. 4 Relationship between DTS and porosity of Biopex $^{\circledR}$ containing 0-0.9 wt\% sodium alginate in its liquid phase when pre-hardened in an incubator kept at $37^{\circ} \mathrm{C}$ and $100 \%$ relative humidity for 1 minute and (O) further kept in the incubator for 7 days or $(O)$ immersed in saline at $37^{\circ} \mathrm{C}$ for 7 days. The relationship between DTS and porosity of TTCP-DCPA type apatite cement ( obtained in our previous study ${ }^{10}$ is also shown for comparison. 
was found to follow the equation as shown in Fig. $4^{10)}$. Porosity of apatite cement depends on many factors such as powder to liquid mixing ratio and packing pressure. This empirical equation is valid only when the composition and structure of the porous material are basically the same except for porosity.

Fig. 4 shows the relationship between DTS and porosity for Biopex ${ }^{\circledR}$ containing 0-0.9 wt\% sodium alginate set in the incubator or in saline for 7 days. Dependence of the DTS on porosity varied according to the setting reaction. When setting was in the incubator (1), decrease of DTS hinged not on the change in porosity as expressed by the above equation. As stated above, the decrease should be due to the limited transformation to apatitic mineral or penetration of liquid into the cement paste. In contrast, relationship between DTS and porosity for Biopex ${ }^{\mathbb{B}}$ in saline (O) was similar to that observed in the case of TTCP-DCPA type apatite cement, except that Biopex ${ }^{\circledast}$ showed lower DTS value. This indicates that the decrease in DTS value of Biopex ${ }^{\mathbb{B}}$ containing smaller amount of sodium alginate was due to increase in porosity of the set mass. Two reaction pathways are thought to proceed competitively when the cement paste is exposed to body fluid, one of which is the setting reaction and the other is the penetration of body fluid into the cement paste. Penetrated body fluid will increase the porosity of apatite cement and if the penetrated liquid is large in amount, the paste would be washed out. Sodium alginate is very effective in preventing the penetration of liquid into the paste. However, smaller amount of sodium alginate may not be enough to prevent liquid penetration into the paste, hence resulting in a set mass with larger porosity.

In conclusion, it was indicated that added sodium alginate was effective to increase the mechanical strength of Biopex ${ }^{\circledR}$ by inhibiting liquid penetration into its paste when it is exposed to body fluid.

\section{ACKNOWLEDGEMENTS}

This study was supported in part by a Grant-in-aid for Scientific Research from the Ministry of Education, Sports, Culture, Science and Technology, Japan.

\section{REFERENCES}

1) Monma H, Kanazawa T. The hydration of a tricalcium phosphate. Yogyo-Kyokai-Shi 1976; 84: 209-213.

2) Brown WE, Chow LC. Paste as Mineralizers and Cements. US Patent No. 4-612-053 (1986).

3) Brown WE, Chow LC. "A New Calcium Phosphate, Water-setting Cement" in Cements Research Progress, American Ceramic Society, Westerville (OH), 1987; pp.351-379.

4) Ishikawa $\mathrm{K}$, Takagi $\mathrm{S}$, Chow LC, Ishikawa $\mathrm{Y}$.
Properties and mechanisms of fast-setting calcium phosphate cements. J Mater Sci: Mater Med 1995; 6: 528-533.

5) Ishikawa K, Miyamoto $Y$, Kon M, Nagayama M, Asaoka K. Non-decay type fast-setting calcium phosphate cement: composite with sodium alginate. Biomaterials 1995; 16: 527-532.

6) Constantz BR, Ison IC, Fulmer MT, Poser RD, Smith ST, VanWagoner M, Ross J, Goldstein SA, Jupiter JB, Rosenthal DI. Skeletal repair by in situ formation of the mineral phase of bone. Science 1995; 267: 17961799.

7) Kurashina K, Kurita H, Kotani A, Takeuchi H, Hirano M. In vivo study of a calcium phosphate cement consisting of alpha-tricalcium phosphate/dicalcium phosphate dibasic/tetracalcium phosphate monoxide. Biomaterials 1997; 18: 147-151.

8) Yokoyama A, Yamamoto S, Kawasaki T, Kohgo $T$, Nakasu M. Development of calcium phosphate cement using chitosan and citric acid for bone substitute materials. Biomaterials 2002; 23: 1091-1101.

9) Driessens FCM, Boltong MG, Bermudez O, Planell JA, Ginebra MP, Fernandez E. Effective formulations for the preparation of calcium phosphate bone cements. J Mater Sci: Mater Med 1994; 5: 164-170.

10) Ishikawa K, Asaoka K. Estimation of ideal mechanical strength and critical porosity of calcium phosphate cement. J Biomed Mater Res 1995; 29: 1537-1543.

11) Ishikawa $K$, Miyamoto $Y$, Takechi M, Ueyama $Y$, Suzuki K, Nagayama M, Matsumura T. Effects of neutral sodium hydrogen phosphate on setting reaction and mechanical strength of hydroxyapatite putty. $J$ Biomed Mater Res 1999; 44: 322-329.

12) Ooms EM, Wolke JG, van de Heuvel MT, Jeschke B, Jansen JA. Histological evaluation of the bone response to calcium phosphate cement implanted in cortical bone. Biomaterials 2003; 24: 989-1000.

13) Ooms EM, Egglezos EA, Wolke JG, Jansen JA. Softtissue response to injectable calcium phosphate cements. Biomaterials 2003; 24: 749-757.

14) Dickson KF, Friedman J, Buchholz JG, Flandry FD. The use of BoneSource hydroxyapatite cement for traumatic metaphyseal bone void filling. J Trauma 2002; 53: 1103-1108.

15) Yetkinler DN, Goodman SB, Reindel ES, Carter D, Poser RD, Constantz BR. Mechanical evaluation of a carbonated apatite cement in the fixation of unstable intertrochanteric fractures. Acta Orthop Scand 2002; 73: 157-164.

16) Arriaga MA, Chen DA. Hydroxyapatite cement cranioplasty in translabyrinthine acoustic neuroma surgery. Otolaryngol Head Neck Surg 2002; 126: 512517.

17) Saito $T$, Kin $Y$, Koshino $T$. Osteogenic response of hydroxyapatite cement implanted into the femur of rats with experimentally induced osteoporosis. Biomaterials 2002; 23: 2711-2716.

18) Welch RD, Berry BH, Crawford K, Zhang H, Zobitz M, Bronson D, Krishnan S. Subchondral defects in caprine femora augmented with in situ setting 
hydroxyapatite cement, polymethylmethacrylate, or autogenous bone graft: biomechanical and histomorphological analysis after two years. J Orthop Res 2002; 20: 464-472.

19) Ooms EM, Wolke JG, van der Waerden JP, Jansen JA. Trabecular bone response to injectable calcium phosphate (Ca-P) cement. J Biomed Mater Res 2002; 61: $9-18$.

20) Baker SB, Weinzweig J, Kirschner RE, Bartlett SP. Applications of a new carbonated calcium phosphate bone cement: early experience in pediatric and adult craniofacial reconstruction. Plast Reconstr Surg 2002; 109: 1789-1796.

21) Miyamoto $Y$, Ishikawa $K$, Takechi $M$, Yuasa $M$, Kon M, Nagayama M, Asaoka K. Non-decay type fastsetting calcium phosphate cement: setting behavior in calf serum and its tissue response. Biomaterials 1996; 17: $1429-1435$.

22) Tanaka S, Kishi T, Shimogoryo R, Matsuya S, Ishikawa K. Biopex ${ }^{\circledR}$ acquires anti-washout properties by adding sodium alginate into its liquid phase. Dent Mater J 2003; 22: 301-312.

23) Miyamoto $\mathrm{Y}$, Ishikawa $\mathrm{K}$, Takechi $\mathrm{M}$, Toh $\mathrm{T}$, Yoshida Y, Nagayama M, Kon M, Asaoka K. Tissue response to fast-setting calcium phosphate cement in bone. $J$ Biomed Mater Res 1997; 37: 457-464.

24) Takechi M, Ishikawa K, Miyamoto $Y$, Nagayama M, Suzuki K. Tissue responses to anti-washout apatite cement using chitosan when implanted in the rat tibia. J Mater Sci: Mater Med 2001; 12: 597-602.

25) Ueyama $\mathrm{Y}$, Ishikawa $\mathrm{K}$, Mano $\mathrm{T}$, Koyama $\mathrm{T}$, Matsumura $\mathrm{T}$, Suzuki $\mathrm{K}$. Initial tissue response to anti-washout apatite cement in the rat palatal region: comparison with conventional apatite cement. J Biomed Mater Res 2001; 55: 652-660.

26) Ishikawa $\mathrm{K}$, Miyamoto $\mathrm{Y}$, Toh $\mathrm{T}, \mathrm{Yuasa} \mathrm{T}$, Ito $\mathrm{A}$, Nagayama M, Suzuki K. Fabrication of Zn containing apatite cement and its initial evaluation using human osteoblastic cells. Biomaterials 2002; 23: 423-428.

27) Oda M, Kaku T, Ookubo A, Matsuya S, Ishikawa K. The effects of hardening environment on the conversion to apatite and the mechanical strength of apatite cement. J J Soc Oral Impl 2003; 16: 400-408.

28) Fukase $Y$, Eanes ED, Takagi S, Chow LC. Setting reactions and compressive strength of calcium phosphate cement. J Dent Res 1990; 69: 1852-1856.

29) Miyamoto $Y$, Ishikawa $K$, Fukao $H$, Sawada $M$, Nagayama M, Kon M, Asaoka K. In vivo setting behavior of fast-setting calcium phosphate cement. Biomaterials 1995; 16: 855-860.

30) Ishikawa K, Miyamoto $Y$, Takechi M, Ueyama $Y$, Suzuki K, Nagayama M, Matsumura T. Effects of neutral sodium hydrogen phosphate on setting reaction and mechanical strength of hydroxyapatite putty. $\mathrm{J}$ Biomed Mater Res 1999; 44: 322-329.

31) Fujisawa K, Sugawara A, Kusama K, Nishiyama M, Murai S, Takagi S, Chow LC. Fluorescent labeling analysis and electron probe microanalysis for alveolar ridge augmentation using calcium phosphate cement. Dent Mater J 2002; 21: 296-305.

32) Tsunoda M. Degradation of poly(DL-lactic acid-coglycolic acid) containing calcium carbonate and hydroxyapatite fillers - effect of size and shape of the fillers. Dent Mater J 2003; 22: 371-382.

33) Arita K, Lucas ME, NishinoM. The effect of adding hydroxyapatite on the flexural strength of glass ionomer cement. Dent Mater J 2003; 22: 126-136.

34) Ban S, Kamiya A, Sonoda T. Calcium-ion incorporation into titanium surfaces accompanied by electrochemical apatite-deposition. Dent Mater J 2002; 21: 306313.

35) Tamura Y, Yokoyama A, Watari F, Kawasaki K. Surface properties and biocompatibility of nitrided titanium for abrasion resistant implant materials. Dent Mater J 2002; 21: 355-372.

36) Nagai M, Hayakawa T, Fukatsu A, Yamamoto M, Fukumoto M, Nagahama F, Mishima H, Yoshinari M, Nemoto K, Kato T. In vitro study of collagen coating of titanium implants for initial cell attachment. Dent Mater J 2002; 21: 250-260.

37) Kon M, Hirakata LM, Miyamoto Y, Kawano F, Asaoka K. Surface-layer modification of hydroxyapatite ceramic with acid and heat treatments. Dent Mater J 2002; 21: 170-180.

38) Ishikawa K, Miyamoto $Y$, Suzuki K. Mechanism of the inflammatory reaction of conventional calcium phosphate cement. Key Eng Mater 1997; 301-304.

39) Yamane $M$. The role and characteristic of gypsum products in dentistry. J Soc Mater Sci Jpn 1980; 29: 421-427. 